\title{
Imágenes de la otredad. Arte, política y cuerpos residuales en Daniel Santoro \\ Laura Ruiz *
}

\begin{abstract}
Resumen: En este artículo se analiza la obra pictórica de Daniel Santoro con el fin de examinar el relato de determinados cuadros en particular y de todos ellos como serie. Se toma en consideración el cuerpo social y político representado para analizar la socialización del concepto de creación en el ida y vuelta entre la historia, la sociedad y el artista. En esta articulación se analiza, en el discurso visual, la irrupción de lo otro como barbarie, como exceso o como cuerpos residuales. Esta intrusión opera para desmontar una naturalizada armonía preexistente en un mundo político y simbólico en el que lo reprimido regresa como mito. Los relatos pictóricos ponen una forma o un estado nostálgico del pasado y de búsqueda de lo perdido, no a modo de lamento sino de propuesta de lucha por deshacer una imagen y presentar otra en la escala de valores imaginativos.
\end{abstract}

Palabras clave: arte pictórico - civilización/barbarie - mito - mundo político - mundo simbólico - otredad - peronismo.

[Resúmenes en inglés y portugués en las páginas 264-265]

${ }^{(*)}$ Doctora en Literaturas Latinoamericanas (University of Florida, Gainesville, EE.UU.), Magíster en Literaturas Latinoamericanas (Michigan State University, East Lansing, EE.UU). Licenciada en Letras Universidad Nacional del Comahue, Neuquén. Docente de la Universidad de Palermo en el Departamento de Investigación y Producción de la Facultad de Diseño y Comunicación. Ganadora de Magna Cum Laude por mejor promedio de la colación 1998 de esa Universidad. Docente en distintas universidades de Estados Unidos y de Argentina. Investigadora de la Universidad Nacional del Comahue. Desde 2011 es docente del Posgrado del Instituto del Servicio Exterior de la Nación, Cancillería Argentina. A partir de 2012 es profesora titular en dicho Instituto.

El recorrido sincrónico de la obra de Daniel Santoro (Buenos Aires, 1954) muestra un aparente quiebre temático a partir del año 2001. En plena explosión de la crisis económica, política y social provocada en Argentina por las políticas neoliberales impuestas diez años antes, Santoro empuja a la superficie del arte pictórico una serie titulada Un mundo peronista. A partir de este año, la crítica y el mismo artista han señalado el ingreso de un núcleo genético que no había sido trabajado en las artes plásticas argentinas: el peronismo. Santoro articula su obra alrededor del eje dicotómico civilización/barbarie, que ha atra- 
vesado toda la historia argentina desde 1845 y, según manifiesta, también su obra. El peronismo se posiciona simbólicamente como el hecho bárbaro que irrumpe, con sus zonas oscuras, en espacios culturales de los que siempre había sido excluido.

Sin embargo, si se toma como bisagra el año 2001 y se transita la obra de Santoro en un recorrido cronológico inverso, se advierte que la otredad funcionó siempre como retícula conceptual. Se exhibe, sobre todo en las muestras de1991 y 1992, el topos de un mundootro. Es, principalmente, un universo "oriental", tratado no solo como lugar ajeno, exótico e inquietante para la alta cultura porteña asistente a las galerías, sino como la construcción de una entidad geográfica condensadora de una constelación de sentidos: las muestras de esos años trataban sobre la cábala, los ideogramas chinos, el taoísmo. También se vieron dos intentos simbólicos de fusiones de lo occidental y oriental a partir de íconos como Carlos Gardel y las figuras de los samuráis que pintaba el japonés Ukiyo'e, y de las cosmogonías de la tradición hermética con lugares arquetípicos urbanos, tales como los bares y la avenida Corrientes de la ciudad de Buenos Aires.

La inserción de Oriente, lo oriental, en el relato universal, dio lugar a la corriente de estudio que Edward Said denominó orientalismo. La cultura hegemónica occidental y cristiana, en su posición de imperio fijó el rol que Oriente desempeñaría en él y vinculó al orientalismo con la política, la ideología y la lógica del poder (Said, 2002, p. 49).

Para Europa, Oriente, además del espacio geográfico donde estaban sus colonias más antiguas y más grandes, fue el origen de sus lenguas y civilizaciones. También fue su adversario cultural y se constituye en representación de una de sus imágenes más repetidas y fuertes de lo otro. Según Said, Europa se ha definido histórica, social y culturalmente por contraposición a tal idea y a su experiencia de Oriente. Lo oriental, como lo otro, define, confronta y constituye a Occidente en tanto entidad cultural, no solamente geográfica e histórica sino también como generadora de una relación de poder entre ambos (Said, 2002, p. 25). La fuerza institucional de Occidente colocó lo oriental en el lugar de lo exótico, inescrutable, lo poco fidedigno y demás afirmaciones acerca de un imaginario que le era ajeno. Con esta argumentación teórica de apoyo, lo que se ha visto como un quiebre en la serie pictórica de Santoro, aparece como una continuidad ideológica: la cosmovisión oriental le sirvió para fundamentar su concepción del peronismo: tomó del taoísmo el concepto de la dualidad del yin-yang que funcionan en su origen como motor y no como par de opuestos. Según Santoro, son dos fuerzas fundamentales complementarias más que opuestas, que funcionan en una dínamo y que se incorporaron a la historia nacional como nuestro dilema civilización / barbarie. El peronismo, en tanto movimiento cultural más que político, hace de esta dicotomía un motor.

En este período, Santoro también trabaja con el número tres en varias direcciones, el de la cábala y el árbol de la vida con las tres ramas: la izquierda que representa la compasión, la derecha que representa la severidad y su centro que es el vacío. En uno de sus ensayos, el artista alega que la energía zigzaguea de un lado a otro buscando su equilibrio y que intenta quedarse en el centro donde nunca va a poder permanecer (Santoro, 2006). Esta cosmovisión, que difiere de nuestra forma dicotómica de pensamiento, le permite entender al movimiento peronista como la tensión entre la izquierda y la derecha, lo cual justificaría su militancia en el peronismo emplazado en la Tercera posición de un mundo polarizado entre el capitalismo y el comunismo. El número tres, además, representa las 
tres ramas del movimiento: la política, la sindical y la femenina. Afirma que el justicialismo habita el vacío que se produce entre la izquierda y la derecha, como una trascendencia de los opuestos. Con este criterio, el movimiento peronista funciona como sutura entre civilización y barbarie, tema central para construir un perfil identitario nacional. El peronismo puede oscilar entre ser agente civilizador o mensajero de la barbarie (Santoro, 2010) y es el vacío o bien que todo lo traga o bien factible de llenar con diversos sentidos. Sin embargo, en la historia y en la sociedad argentina, el peronismo marcó una ruptura que, durante varios años, va a polarizar la vida política y va a reactivar una lectura del eje civilización / barbarie.

\section{El peronismo, lo otro, la otredad}

Desde su origen en 1945, la sociedad argentina puso en debate la referencia a las "masas bárbaras" irreductibles a la cultura (Svampa, 1994, p. 269). A partir de la fecha clave del 17 de octubre, la mayoría peronista pasó a encarnar el fantasma de la barbarie y allí quedó instalada en el modelo de lectura dicotómica. Se inscribía, de esta manera, en la línea procedente de Juan Manuel de Rosas que tuvo su continuidad en la de la "chusma" radical de los años treinta.

Para la socióloga Maristella Svampa (1994), Juan Perón introduce, en su lectura de lo social, la manera en que su discurso intentó resolver la paradoja formulada al inicio de cómo y por qué el peronismo vehiculizó el fantasma de la barbarie (283). Mientras que el discurso de Perón buscaba constituir al bárbaro como pueblo, y nuevas representaciones se articulaban en un espacio de oposiciones múltiples, del lado opuesto, la "unidad nacional" suponía la imposibilidad de su coexistencia con el otro.

El 17 de octubre de 1945, una enorme movilización popular avanzó hacia la exclusiva ciudad de Buenos Aires para reclamar la liberación de Perón, detenido en la isla Martín García. Este avance fue resignificado por la clase alta como una invasión amenazante de la Argentina mestiza y pobre, a partir de lo cual se la comenzó a constituir como una otredad negativa (Feierstein, 2000).

En la historia del sometimiento de los pueblos, diversas configuraciones de lo otro se fueron constituyendo históricamente en estrategias de bloqueo y desarticulación en los procesos de conformación de las relaciones humanas. Las fuerzas dominantes comienzan a implementar acciones en que la percepción de igualdad entre el ilustrado con el ignorante, el civilizado con el salvaje o bárbaro va desapareciendo según se transforman las formas simbólicas de construcción de la otredad en los últimos siglos (Feierstein, 2000, pág. 33). Frente a esta situación, la fuerza social dominante comienza con la implementación de acciones progresivas de tipo esporádico contra el sujeto social construido como otredad, con objetivos tales como profundizar el proceso de demarcación del otro, cuyo resultado es situarlo a la defensiva. Una vez que lo otro se acepta como existencia negativa, "se intenta regular sus espacios, buscando limitar sus movimientos, sus zonas de desarrollo y sus propias prácticas" (Feierstein, 2000, pág. 41). El reordenamiento cartográfico pretende 
delimitar el espacio por el que puede transitar ese otro diferente: hay territorios permitidos y territorios prohibidos.

Para Feierestein, la construcción de otredades negativas es un momento conceptual previo que posibilitó la perpetración de los genocidios de la era moderna. Para este investigador, los modelos de construcción de identidad y alteridad, de representaciones simbólicas que nos sugieran ciertos modos de percibirnos a nosotros - nuestra propia identidad- son un modo de construir aquello que colocamos en el rol de alteridad, a lo que se añade, de manera simultánea o consecutiva, "la operatoria de negativización de la misma" (Feierstein, 2007, p. 395).

La construcción social de una otredad negativa requiere, como antítesis, la demarcación de "identidades por exclusión”. Tal proceso es una manera de constituir la representación de la identidad propia que necesita negar la multiplicidad (parte fundamental de todo proceso identitario) y concentrar tal identidad en uno solo de sus componentes. En la modernidad, en las relaciones entre países, ese componente por antonomasia ha sido la identidad nacional, articulada en distintos sentidos según los casos (Feierstein, 2007, p. 396).

Para poder implementar los procesos de deshumanización del otro, el requisito indefectible es la posibilidad de "deshacerse" de la alteridad que está presente en cada individuo, que compone toda identidad y todo Estado-nación. Así, al ajenizar a la víctima, al externalizarla es posible poner en funcionamiento más ajustadamente los mecanismos que Zygmunt Bauman calificó como de "adiaforización": la indiferencia hacia el otro que produce su extrañeza, una actitud que tiende a conjugarse con la negativización que opera sobre quienes deben desempeñarse con perpetradores directos" (Feierstein, 2007, p. 396). La necesidad de delimitar identidades está considerada como constituyente de la modernidad, los modos de la negativización han transitado diversas estructuraciones, desde la elemental división entre "civilización y barbarie" hasta las más sofisticadas y recientes teorías raciales -el nazismo, por ejemplo- (Feierstein, 2007, p. 395).

A partir del 17 de octubre de 1945, la multitud pobre que marchaba hacia la Plaza de Mayo de Buenos Aires fue construida como una otredad negativa, tanto en lo simbólico como en lo material, por parte de las fuerzas dominantes. En el plano del lenguaje fue el "aluvión zoológico", creación léxica de Eduardo Sanmartino, un legislador de la Unión Cívica Radical del momento, que terminó atravesando todos los espacios discursivos de la "civilidad". Tanto la izquierda de la época, como la derecha abundaron en la adjetivación negativa: lumpen-proletariado, cabecitas negras, descamisados, pasa a ser, en otros términos, la barbarie no extirpada, la temida barbarie "residual" (Svampa, 1984, p. 320).

En 1945, el comité de Coordinación de la Facultad de Ciencias Exactas, elaboró y distribuyó un volante que decía: "Ciudadanos: Buenos Aires ha sido invadida por hordas bárbaras que, al amparo policial, han cometido toda clase de desmanes y atropellos. Ocupe su puesto en la lucha contra la dictadura” (Svampa, 1984, p. 320). En la misma línea, el periódico oficial del Partido Comunista, el 24 de octubre de ese año publicó: "Pero también se ha visto otro espectáculo, el de la horda de desclasados haciendo vanguardia de presunto orden peronista. Los pequeños clanes con aspecto de murga que recorrieron la ciudad no respetan ninguna clase de la sociedad argentina. Es el malevaje reclutado por la policía y los funcionarios de la Secretaría de Trabajo y Previsión para amedrentar a la 
población (Ramos, A. Revolución y contrarrevolución en Argentina, p. 599)” (Svampa M. , 1984, p. 321).

Ezequiel Martínez Estrada, calificó a esos sectores marginales de "turba", "populacho desdichadamente mayoritario", "resentidos", "irrespetuosos iconoclastas". Para este escritor, se trataba de "otro país", de un "sedimento social" que no puede ver como pueblo sino como "una fuerza tremenda y agresiva", una "invasión mestiza" (Svampa, 1984, p. 330). Instalada en la violencia verbal, la oposición pueblo/cultura pone de un lado a la vitalidad de la montonera y a la cultura y a la civilización del otro; trae a escena un estado de situación bifronte: la irracionalidad de las masas en franca ocupación y el miedo de la argentina europea en notorio repliegue.

Así, el vector civilización/barbarie se cristaliza en un conjunto de cuadros en la historia de la pintura nacional, con múltiples significaciones. En 1892, Ángel Della Valle pintó La vuelta del malón, cuadro fundante de nuestra identidad que sirvió para justificar la conquista del desierto de Julio Argentino Roca y el consecuente exterminio de los pueblos originarios (Santoro, 2010). Este clásico inspiró una serie de reformulaciones en distintos artistas plásticos argentinos. La primera reescritura o reinterpretación que hace Santoro es en el año 2009 y la tituló Malón y concepto espacial. El concepto espacial, en claro intertexto con los cuadros del pintor rosarino Lucio Fontana (1899-1968 en Italia), se resignifica en el cuadro de Santoro como un tajo pintado. El malón-que Santoro define como "protoperonismo"- se detiene frente al espacio que queda definido por el agujero negro, un gesto aparentemente contemporáneo, que multiplica sus posibilidades sémicas. Santoro ha reinterpretado la serie de Fontana, iniciada en 1949, como el cuchillo del latinoamericano que tajea la tela europea.

Hay otras dos reformulaciones del cuadro de Della Valle que pinta Santoro: Victoria Ocampo observa la vuelta del malón (óleo, 2011) y Victoria Ocampo observa la otra vuelta del malón (acrílico, 2011). En el óleo, el hemisferio izquierdo está totalmente ocupado por una construcción modernista o racionalista que contiene a una Victoria Ocampo observando o impidiendo el avance de un malón, ubicado en el hemisferio derecho del cuadro. El malón se dirige inexorablemente hacia la zona más oscura del cuadro. Aquí, como en muchas de sus obras, hay una coincidencia de temporalidades. Ocampo vivió entre 1890 y 1976 y los últimos malones se produjeron hasta finales de 1870. A diferencia de la versión de Della Valle, el malón está enfocado frontalmente y no como una cámara de costado que lo sigue en su avance. Esta posición del enfoque pareciera marcar el límite: hay un duelo en el espacio, en la estética entre civilización y barbarie que no se resuelve.

En esta antítesis -que había sido apropiada por el discurso opositor al peronismo-, Santoro opta por incorporar a la pintura argentina ese malón impedido de avanzar por la luz racionalista que trae consigo Victoria Ocampo. Coloca el costado bárbaro de la cultura argentina en el centro del debate artístico: el peronismo de su década más feliz, la de 19451955. Si este acto artístico ha sido leído en clave nostálgica por aquel tiempo pasado, significado como el paraíso perdido en el que la concepción de un Estado de Bienestar sigue presente en el imaginario social, también se lo puede considerar como una provocación y una afirmación: por un lado, política e ideológica ya que reafirma que el peronismo pertenece a esa época de reivindicaciones y reparaciones de la primera etapa y no a la de los 
años noventa, la del neoliberalismo menemista que accionó en contra de todos los principios de la doctrina justicialista por los que accedió al gobierno en 1989. Y, por otro lado, el impulso provocador e irritante de estetizar al peronismo y de insertarlo en el exclusivo mundo de la pintura. Los artistas plásticos argentinos nunca, o muy pocas veces, habían expresado el movimiento peronista porque es "una cosa de negros" (Santoro, 2010). Lo que tiene de impuro, de ominoso, de oscuro y de excesivo es lo que convoca a Santoro a hacerlo irrumpir como una perturbación. A cruzar la frontera.

A partir del 2001, las muestras más destacadas que siguieron fueron: Leyenda del bosque justicialista (Galería Palatina, 2004); Dibujos, jardines justicialistas, en el Instituto Universitario Nacional de Arte (IUNA) en el mismo año. En 2005, el Museo Caraffa de la provincia de Córdoba presentó Utopía justicialista con un objeto caído y completaba la muestra una instalación donde podía verse una reproducción a escala del avión Pulqui.

\section{El exceso: cuerpos residuales}

La historia de las artes visuales es la historia del poder. Ellas siempre han existido dentro de cierto espacio acotado, en un principio mágico o sagrado y lo han hecho por fuera de los contornos del resto de la realidad circundante para que, precisamente, pudieran ejercer algún poder sobre la vida de todos los demás. La autoridad del arte fue inseparable de la autoridad de ese espacio de poder (Berger, John et all, 2005, p. 40). En un gesto que lo emparenta con la vanguardia, Santoro reclama para sí la autonomía dentro del campo artístico. Reivindica el derecho a ser curador y juez de su producción pictórica, de producir los criterios de percepción y de valoración de sus productos. Quiere generar la imagen de sí mismo y de su trabajo y conseguir un efecto en el que se refracten los demás agentes involucrados en el campo. Sus repetidas manifestaciones oponiéndose a quedar atrapado en las imposiciones del mercado del arte, ponen en escena esta tensión con el poder. Se niega a hacer del oficio de pintor su medio de vida porque, asegura, los temas que trabaja tienen muchos inconvenientes desde el punto de vista del mercado. En las artes visuales, el tópico peronismo ni es frecuente ni es cómodo. Desde los años sesenta, lo que se había manifestado como arte político o comprometido fue la corriente de izquierda, sobre todo la de los pintores vinculados al Partido Comunista como Antonio Berni (1905-1981), pero hasta ahora el movimiento peronista siempre fue el gran ausente, la falta. Si ingresa en las artes visuales, necesita ser explicado, motivo por el cual Santoro decidió incorporar a sus cuadros una tarjeta escrita con una extensa descripción.

Santoro es, también, su propio curador porque no quiere ceder a ninguna institución cultural la decisión de cuáles cuadros suyos merecen ser expuestos. Según el pintor, los curadores le han dicho que hay cuadros que se molestan entre sí y que no pueden exponerse simultáneamente, pero él se resiste a entrar en el camino de los deseos ajenos: sus cuadros son los que tienen que estar porque cuentan una historia y funcionan en su conjunto (Santoro, 2010). 
De la iconografía peronista presente en los cuadros, Eva Perón es el personaje central, en tanto mito emblema del movimiento. En la historia argentina, Eva fue también el símbolo del exceso de una legitimación asociada a la irrupción de la barbarie (Svampa, 1994, p. 311). También le dedica gran espacio al Pulqui, primer avión a reacción hecho totalmente en Argentina durante 1951 y desactivado después del golpe de estado de 1955. Pinta los símbolos del primer peronismo con una nitidez perturbadora, con una literalidad conturbadora que escatima el nivel metafórico: el guardapolvo blanco, las heladeras, la máquina de coser, el automóvil justicialista, los chalecitos californianos. Pareciera que la intención es detener al mundo en la felicidad, congelarlo a pesar del riesgo que corre de ahistoricismo (Rojas, 2008).

Pero, indudablemente, el trabajador fue la figura emblemática del peronismo, no sólo por su protagonismo en los acontecimientos inaugurales del movimiento, sino también como expresión cabal del concepto de "justicia social” y como símbolo de la pujanza industrial que se propugnaba desde el gobierno (Gené, 2007). También la niñez adquirió una centralidad fundamental en el discurso gráfico y en el imaginario de la época, entre otros motivos por resultar la principal beneficiaria de un Estado de Bienestar protector y maternal, bajo la figura tutelar y omnipresente de Eva Perón.

Santoro condensa estas dos figuras paradigmáticas en una díada narrativa que recorre su obra: La leyenda del Descamisado Gigante y La leyenda de la mamá de Juanito Laguna.

El Descamisado Gigante tiene su antecedente en el proyecto de 1952 de un monumento en homenaje al trabajador o al descamisado y que formaría parte de un conjunto arquitectónico mayor. El proyecto - del que aún se conservan maquetas y bocetos- se truncó en 1955, cuando ya tenía los basamentos construidos. El monumento terminado iba a tener una altura de 137 m y quedaría emplazado en las cercanías de la residencia presidencial, ubicación que le permitiría ser visto, incluso, por los viajeros que llegaran en barco al puerto de Buenos Aires.

El término "descamisado" aparece por primera vez en la crónica del diario El Mundo del 18 de octubre de 1945 y fue incorporado en el discurso de Evita para referirse a "mis pobres", a quienes también nombró "mis grasitas". Con la puesta en escena del descamisado en una nueva serie de valores imaginativos, Santoro repara la frustración material del símbolo. En la serie pictórica se puede ver al descomunal trabajador en un transitar plácido, que se adivina pausado y hasta indiferente: es un gigante protector, en defensa del edificio de la Confederación General del Trabajo (CGT) contra los ataques aéreos del golpe de estado del 55. Se traba en franca lucha de clases en un cuerpo a cuerpo contra el "gorila" King Kong. Se lo ve cuidando los chalecitos californianos de las familias peronistas, otorgados por el Estado de Bienestar. Se lo ve protegiendo la Ciudad Infantil, emprendimiento de la Fundación Eva Perón. El coloso atraviesa un "jardín cultivado", en el que se puede identificar bustos de los personajes pertenecientes a la "alta cultura" porteña como Jorge Luis Borges y Victoria Ocampo en juego con la polisemia de cultura/cultivar. Se lo ve, también, descubriendo en un claro del bosque justicialista a una esfinge nutricia de Eva Perón. Merodea los alrededores de la Isla de los Muertos, camina sobre un campo de soja transgénica, arrasando el cultivo, pero con expresión relajada. En muchos de estos cuadros el descamisado aparece emboscado, atrapado entre las ramas de árboles amena- 
zadores (hay tres versiones de este tema: una de 2006 y dos de 2008). Se lo ve dormido en el bosque. También, como San Sebastián, mártir de la mitología católica, asaeteado por los romanos por comprometerse con la política de Cristo. Este cuadro de Santoro -Descamisado Gigante Martirizado del año 2008- replica exactamente la misma iconografía de las representaciones del mártir cristiano: San Sebastián está atado a una columna, con un edificio en ruinas de fondo y a sus pies, la cabeza ladeada, la boca abierta y la mirada perdida hacia el cielo y su cuerpo atravesado por flechas. El Descamisado está amarrado al Obelisco, detrás se ve el edificio del hospital de la Liga Argentina contra la Tuberculosis -proyecto retomado por el gobierno de Juan Perón en 1947 y abandonado en 1955 por el golpe de estado- en la misma posición corporal y atravesado por saetas. Según su hagiografía, San Sebastián fue dado por muerto, pero sus amigos lo rescataron, lo ocultaron y lo curaron y él retomó la lucha por sus creencias. Después del 55, el descamisado que fue preso, perseguido y dado por muerto regresa como mito en el nivel simbólico de la mano del pintor. No aterroriza por su actitud más bien plácida y relajada, sino por su monumentalidad, su cuerpo desmedido.

Con la Leyenda de la mamá de Juanito Laguna Santoro se inscribe en una corriente artística que no sólo es estética sino de fuerte contenido social. Berni crea el personaje de Juanito Laguna como paradigma de la explotación infantil y de la pobreza en América Latina. Pinta la serie hacia fines de los años cincuenta y principios de los sesenta, borrándoles a los personajes los rastros de un probable pasado peronista. La torsión de Santoro es (pro)poner en el centro de la escena a la mamá de Juanito y "peronizarla". Si en la obra de Berni la mamá de Juanito Laguna se llama Ramona Montiel, en un gesto de universalización, en la obra de Santoro se anonimiza y simplemente es "la mamá de". Ella está representada como una adolescente, niña escolar, con el delantal blanco que borraba las diferencias sociales en la escuela pública, obligatoria y gratuita que el gobierno peronista promovía en línea con la tradición de escuela del Estado laica y gratis iniciada, en la Argentina, desde fines del siglo XIX con la promulgación de la Ley 1420. La mamá de Juanito Laguna casi siempre está pintada con una banda de luto en su brazo, en memoria de la muerte de Evita. La leyenda pictórica cuenta las distintas instancias de la vida de la mamá de Juanito, como un Vía Crucis. Aparece en un bosque rescatada por el espíritu del lugar; en distintas vivencias en el bosque justicialista donde la ataca una pantera, el mismo animal que, en otro cuadro, la cuida. Está en un encuentro en el bosque con el papá de Juanito; de camino hacia la Ciudad Infantil acompañada por Evita; en su último paseo con Eva, durante los bombardeos a la Plaza de Mayo. En este momento se destruyen el brazo protector del Estado y la mano conductora de Evita, entonces, las representaciones tienen como escenario las afueras de los límites protectores de la Ciudad Infantil. Juanito Laguna nace a la orilla del río, al lado de un muro que deja ver construcciones de esa ciudad a la que él ya no pertenecerá. Hay un fondo de aviones bombardeando y su madre, desnuda, sentada sobre el delantal blanco con el brazalete de luto en la manga. Es el 55, y el niño que nace ya no asistirá a la escuela ni recibirá la protección del estado, motivo por el cual aparecerá abandonado en los basurales de José León Suárez, tal como lo concibió Berni. La madre adolescente muere ahogada. En un cuadro se ve su cuerpo flotando en el río y en otro, un descamisado en un bote rescata su cadáver del mar, en las costas de Chapadmalal, lugar insigne donde el peronismo construyó las colonias de vacaciones para los niños sin recursos. 
Estos dos emblemas de la iconografía peronista se condensan en un solo cuadro: El descamisado gigante ayuda a cruzar el Riachuelo a la mamá de Juanito Laguna (2006). Es un cuadro muy despojado de la iconografía peronista. Las dos figuras centrales no admiten desviación de la mirada. Ambas coinciden en un espacio y tiempo de poderosa significación: es el 17 de octubre y cruzan, precisamente, el río que delimita el sur de la ciudad de Buenos Aires. En su juego con las temporalidades, Santoro coloca en el mismo momento la gesta inaugural del 17 de octubre de 1945 junto con el texto La Razón de mi Vida, de 1951, y lo hace porque, se podría decir, tal peronismo es atemporal y existe en todo tiempo mítico, circular.

El Descamisado Gigante carga en su hombro izquierdo a la niña-madre, quien atesora el texto doctrinario de Eva Perón, y cruzan el Riachuelo, límite geográfico entre la civilización y la barbarie. Ese día de 1945 se izó el puente Pueyrredón (como se ve al fondo de la tela) para que las multitudes de desclasados que provenían de la provincia no pudieran ingresar la ciudad de Buenos Aires. Pero "el aluvión zoológico", de todas las maneras, cruzó: a nado, en botes, sobre tablones de madera, ayudándose entre sí. En clara alegoría religiosa, el Descamisado está representado como San Cristóbal de Licia, hombre de colosal estatura de la tradición católica que ayudaba a los viajeros a cruzar el río, sentados sobre su hombro. Las representaciones más comunes lo muestran llevando al niño Jesús en su hombro izquierdo, quien le pesaba más que nadie porque cargaba con los pecados del mundo. Se dice que era de origen bárbaro y que murió martirizado por predicar la fe cristiana.

El San Cristóbal de Santoro camina con las piernas sumergidas hasta la rodilla en el agua oscura, pesada del Riachuelo. Detrás, además del puente levantado, se ven las fábricas, difusas, algunas humeantes. La niña va sentada en su hombro izquierdo. Las construcciones a medio hacer, el río, la piel de los personajes, todos en tonos oscuros se iluminan con la camisa y el delantal almidonado de la niña, ambos de blancura extrañamente inmaculada. Ninguno de los dos lleva el brazalete por el luto obligatorio por Evita, como en el resto de las series, porque es un momento de celebración.

El eje temporal antes/ahora, laboriosamente estudiado por distintos autores que lo interpretan en clave nostálgica, se borra en este cuadro para fijarse en un presente en el que convergen muchos "ahora": el relato del peronismo de Santoro, en el que se inscriben estos otros microrrelatos, tiene una temporalidad inquietante y permanente, de fluir circular como lo conciben las culturas orientales. Por ello, Santoro implanta, en muchos de sus cuadros, ideogramas chinos que provocan una desviación de la mirada frontal creando otro foco visual secundario. Los ideogramas actualizan una sensibilidad estereofónica en el receptor: se leen y se miran. El público argentino sabe que el ideograma dice algo, pero no lo entiende, sólo puede observarlo. Así, la realidad es mucho más que lo que aparece, no se puede ilustrar, se inventa, se celebra como sueño o se padece como pesadilla. Para Santoro, el movimiento peronista es cultural y pregna la vida de todos los argentinos; es un exceso que define la búsqueda de una identidad.

Aún hoy (o más aún, hoy), el ingreso del peronismo en el arte resulta perturbador e irritante. Ese pasado que trae a la superficie un estado de inermidad en el panorama político y social y que queda atrapado en una dicotomía cuya resolución pareciera (no) dirimirse en el arte. En un gesto volitivo, Santoro estetiza lo monstruoso, la negrada, los desplazados, los silenciados, los cuerpos residuales para yuxtaponer lo "feo" en el plano de igualdad social con lo "bello". 


\title{
Bibliografía
}

Berger, J. et all. (2005). Modos de ver. Barcelon: Gilli.

Bourdieu, P. (1992). Las reglas del arte. Barcelona: Anagrama.

Catania, R. (21 de febrero de 2010). Entrevista en Los Toldos. Disponible en: roquecatania. blogspot.com.ar

Feierstein, D. (2007). El genocidio como práctica social. Entre el nazismo y la experiencia argentina. Buenos Aires: Fondo de Cultura Económica.

(2000). Seis estudios sobre genocidio. Análisis de las relaciones sociales: otredad, exclusión y exterminio. Buenos Aires: Eudeba.

Gené, M. (1 de junio de 2007). Un mundo feliz. Las representaciones de los trabajadores en el primer peronismo (1946-1955). Disponible en: http://nuevomundo.revues.org/5777

Harmatia.com.ar. (7 de abril de 2011). Disponible en: http://www.youtube.com/watch?v= kcrrdPjcWBo

Punte, M. J. (2010). Huellas del pasado: infancia y narrativa sobre el peronismo. Iberoamericana, LXXVI(232-233), 741-756.

Rojas, D. (2008). La pulsión del peronismo. Conversación entre Daniel Santoro y Horacio González. 24Con.

Said, E. (2002). Orientalismo. Barcelona: Random House.

Santoro, D. (19 de diciembre de 2010). Decime quién sos vos. (E. Aliverti, Entrevistador) (2006). Vacío y plenitud justicialista. Mundo peronista. Buenos Aires: La marca.

Svampa, M. (1984). El dilema argentino: civilización o barbarie. Buenos Aires: Taurus.

\begin{abstract}
Summary: In this article the work of Daniel Santoro are analyzed in order to examine the discourse of certain paintings in particular and all of them as a series. It takes into consideration the represented social and political body to discuss the socialization of the concept of creation in the interaction between history, society and the artist. In this linkage we analyze the emergence of the other as barbaric, as an excess or residual bodies in the visual discourse. This intrusion operates in order to remove a pre-existing harmony in a political and symbolic world in which the repressed returns as myth. Pictorial stories put a shape or a nostalgic state of the past and search for the lost, not by way of regret but proposed fight to undo an image and make another on the scale of imaginative values.
\end{abstract}

Keywords: civilization / barbarism - Myth - otherness - painting art - Peronismo - political world - symbolic world. 
Resumo: Neste trabalho se propõe uma analise da obra pictórica de Daniel Santoro, organizada numa retícula temática e cronológica a fim de examinar o relato de determinadas obras particulares e todos eles como série. Considera-se o corpo social e político representado para analisar a socialização do conceito de criação no indo e vindo entre a história, a sociedade e o artista. Nesta articulação se analisa, no discurso visual, a irrupção do outro como barbárie, como excesso ou como corpos residuais. Esta intrusão opera para desmontar uma naturalizada harmonia preexistente num mundo político e simbólico no qual o oprimido volta como mito. Os relatos pictóricos propõem uma forma ou um estado nostálgico do passado e de procura do perdido, não como um lamento senão de proposta de luta por desfazer uma imagem e apresentar outra na escala de valores imaginativos.

Palavras chave: arte pictórica - civilização / barbárie - mito - mundo político - mundo simbólico - otredade - peronismo. 